\title{
Seizure frequency and obstetric complications at advanced maternal age: a preliminary observational study in women with epilepsy
}

\author{
Hui Gao ${ }^{1+}$, Nanya Hao ${ }^{1+}$, Shanrui Liu² and Dong Zhou ${ }^{1 *}$
}

\begin{abstract}
Background: Seizure control during pregnancy and obstetric outcomes are of important concerns for women with epilepsy (WWE) and their families. Advanced maternal age ( $\geq 35$ years) shows a growing trend in the society with changes of lifestyle, which also occurs in diseased populations. The advanced maternal age is an independent factor for some unsatisfying obstetric outcomes. In this study we explored the seizure control and obstetric complications associated with advanced maternal age in WWE.
\end{abstract}

Methods: This study was based on the epilepsy pregnancy registry at West China Hospital. Patients with epilepsy in this registry who were aged 35 or older when starting pregnancy were included in this study. Their basic demographics and detailed information on epilepsy management and obstetric issues in all trimesters and during 1-year follow-up after birth were documented and reviewed. Data were processed by IBM SPSS version 22.0. The demographic characteristics, seizure frequency, treatment change, obstetric complications, and outcomes were analyzed and compared.

Results: Fifteen patients were included in this study, with an average age of $36.32 \pm 2.39$ years at pregnancy, and $73.33 \%$ of them were primiparas. The change of seizure frequency during pregnancy was not in a clear pattern, but there was an increased incidence of tonic-clonic seizures during the mid-and last trimesters. More than 20\% of the patients had obstetric complications throughout the trimesters, including vaginal bleeding, hypothyroidism, and pre-eclampsia. The pre-eclampsia seemed extraordinarily complicated with other conditions. However, none of the complications were related with malformations or poor outcome of babies after 1-year follow-up.

Conclusion: Advanced maternal age combined with WWE is associated with frequent common obstetric complications. Future controlled studies with large sample sizes are needed to explore the related risks in comparison with other WWE and non-epileptic populations.

Keywords: Women with epilepsy, Advanced maternal age, Obstetric outcome, Seizure control

\footnotetext{
* Correspondence: zhoudong66@yahoo.de

${ }^{+}$Hui Gao and Nanya Hao contributed equally to this work.

'Department of Neurology, West China Hospital, Sichuan University,

Chengdu 610041, China

Full list of author information is available at the end of the article
}

(c) The Author(s). 2021 Open Access This article is licensed under a Creative Commons Attribution 4.0 International License, which permits use, sharing, adaptation, distribution and reproduction in any medium or format, as long as you give appropriate credit to the original author(s) and the source, provide a link to the Creative Commons licence, and indicate if changes were made. The images or other third party material in this article are included in the article's Creative Commons licence, unless indicated otherwise in a credit line to the material. If material is not included in the article's Creative Commons licence and your intended use is not permitted by statutory regulation or exceeds the permitted use, you will need to obtain permission directly from the copyright holder. To view a copy of this licence, visit http://creativecommons.org/licenses/by/4.0/ 


\section{Background}

Women with epilepsy (WWE) are considered to be at a high risk of complications during pregnancy [1], although previous research has not shown a substantial increase of seizure burden during pregnancy [2, 3]. Higher incidence of vaginal bleeding, pre-eclampsia, caesarean section, and premature delivery was observed in most WWE compared to the non-epileptic group [4-6], while some studies found no increased perinatal and neonatal complications [7-10] . In addition, there is a higher rate of major congenital malformation in babies of WWE, which is most likely related to the prenatal exposure to anti-seizure medications (ASM) [11-15].

Advanced maternal age is defined as childbearing in a woman aged 35 or older, raising obstetric concerns which are now becoming a new research field. The growing trend of advanced maternal age can be attributed to the changes in women's lifestyle and roles they play, and the development of advanced technology that aids in childbearing in multiparous women [16]. In China, to fight against the aging society challenge, the "one child one family" has been eliminated, and more families are making their decision to welcome the second child. However, women with advanced maternal age may have more obstetric complications and poorer obstetric outcomes compared with childbearing women under 35 years [17]. A meta-analysis of all the related studies found that the rate of stillbirth is increased in advanced maternal age pregnant women, and the risk increases with increased maternal age [18].

The social and lifestyle changes are also occurring in the WWE population. However, the obstetric risks of WWE in the advanced maternal age have not been well studied. There is a growing need to understand the associated issues with advanced maternal age in WWE. In this study, we set out to explore the seizure control and obstetric complications of WWE in advanced maternal age.

\section{Methods}

\section{The epilepsy pregnancy registry}

The epilepsy pregnancy registry at West China Hospital was established in May 2014, and has been reviewed and approved by the ethics committee. It is a prospective registry based on epilepsy clinic [19]. Women diagnosed with epilepsy at childbearing age were asked to give written informed consent to participate in the registry and renew their information every 3 months at each clinical visit. The entire follow-up included clinical follow-up every 3 months at the outpatient clinic till the delivery, and a final follow-up 1 year thereafter. A management team including experienced epileptologists also checked the status and visits of patients. If a patient missed a clinical visit, they would contact the patient by telephone to collect information.

Each patient was assigned forms $\mathrm{A}-\mathrm{E}$, corresponding to different types of information in various periods during pregnancy. Form A contained basic demographic information (maternal age, education level, place of residence, employment status, marital status), obstetric information (date of last menstrual period, pregnancy plan, and reproductive history), information of epilepsy (duration of epilepsy, epilepsy type, seizure type, baseline seizure frequency before pregnancy, and usage of ASM). Form B documented information in the first trimester, including substance and ASMs exposure, complications, use of folate acid, medical exanimation findings and epilepsy management. Forms $\mathrm{C}$ and $\mathrm{D}$ documented the same information as in form $B$ in the mid- and last trimesters separately. Form D contained delivery information at labor and fetus evaluation at birth. Form E was finished 1 year after birth, focusing on the complications and seizure control after birth, with extra information on breastfeeding, infant growth, malformations, and disease profile.

\section{Patient selection}

Patients starting their pregnancy at the age of 35 or older (according to the date of the last menstrual period before pregnancy) were selected from the registry database. Information of each patient was carefully reviewed. Patients with information available at all three trimesters were included.

All the data were processed by IBM SPSS version 22.0. The demographic characteristics, seizure frequency, treatment change, obstetric complications, and outcomes were described with ratio.

\section{Results}

\section{Demographics and obstetric features}

After removing duplicate records and records with incomplete information in the trimesters, 15 women were finally included in this study. Their average age at pregnancy was $36.32 \pm 2.39$ years, and over half $(53.33 \%)$ of them had a college degree and a stable job.

The majority of them $(11 / 15,73.33 \%)$ were primiparas, four of them (26.67\%) were pluriparous, and $12(80 \%)$ had a history of abortion, mostly more than once. One patient was in gemellary pregnancy. The most common reasons for abortion are societal factors, followed by medical considerations like possibilities of heredity/ medication-caused obstetric complications and abnormal pregnancy (extrauterine pregnancy and pregnancy with an intrauterine device). All the four pluriparous women had vaginal delivery for their first child with no obstetric complications, and all the first children were healthy. 


\section{Seizure frequency during pregnancy}

Seven patients $(46.67 \%)$ had two different seizure manifestations before pregnancy. The seizures included focal bilateral tonic-clonic seizures (54.55\%), generalized tonic-clonic seizures (22.73\%), and focal impaired awareness seizures (18.18\%). The seizure types remained unchanged in each patient, and no new seizure types were documented during the pregnancy.

Combining the seizure types together, the seizure frequency was most common at the monthly level, with two patients having focal impaired awareness seizures several times a day. Nine patients had active epilepsy, two were stable, and four withdrew their ASM under surveillance before pregnancy.

The patients with active epilepsy still had seizures during pregnancy. However, the frequency of seizures changed over time (Table 1), except for one patient who had seizures as the same frequency as previous. The frequency of tonic-clonic seizures increased from yearly level (88.89\%) before pregnancy and at the first trimester to quarterly level at the mid (77.78\%) and last trimesters (55.56\%). The patients with stable disease and ASM withdrawal were generally uneventful, but there was one patient having a tonic-clonic seizure at the last trimester, which directly caused premature delivery with precipitate labor. No status epilepticus was documented for any patient.

\section{Treatment changes during pregnancy}

Before pregnancy, six patients were on monotherapy, five on polytherapy (four having two medications and one having three medications), and four under no medication (seizure free, therefore standard ASM withdrawal was applied). The monotherapy included levetiracetam (LEV), carbamazepine (CBZ), topiramate (TPM), and sodium valproate (VPA), preferably LEV (Table 1 ).

Treatment changed in the group of active epilepsy. Four out of the nine patients stopped medications by themselves to avoid the assumed adverse effects on the fetus. Three resumed their previous drug regimen after visits to epileptologists. One patient was off-medicine during the whole pregnancy, and no increase in seizure frequency was documented for that patient. One patient increased dosage of Lamotrigine in her polytherapy regimen during the first trimester, and then eventually increased dosage of LEV in mid-trimester and Lamotrigine in the last trimester for better seizure control.

Table. 1 Changes of ASM and seizure frequency during different trimesters

\begin{tabular}{|c|c|c|c|c|c|c|c|c|}
\hline NO. & $\begin{array}{l}\text { ASM } \\
\text { before } \\
\text { pregnancy }\end{array}$ & $\begin{array}{l}\text { Seizure } \\
\text { frequency } \\
\text { before } \\
\text { pregnancy }\end{array}$ & $\begin{array}{l}\text { ASM } \\
\text { changes in } \\
\text { the 1st } \\
\text { trimester }\end{array}$ & $\begin{array}{l}\text { ASM changes } \\
\text { in the } 2 \text { nd } \\
\text { trimester }\end{array}$ & $\begin{array}{l}\text { ASM changes } \\
\text { in the 3rd } \\
\text { trimester }\end{array}$ & $\begin{array}{l}\text { Seizure frequency } \\
\text { change in the } 1 \text { st } \\
\text { trimester }\end{array}$ & $\begin{array}{l}\text { Seizure frequency } \\
\text { change in the } 2 \text { nd } \\
\text { trimester }\end{array}$ & $\begin{array}{l}\text { Seizure frequency } \\
\text { change in the } 3 \text { rd } \\
\text { trimester }\end{array}$ \\
\hline 1 & VPA & Yearly & Stop ASM & & VPA resumed & & Increased & Increased \\
\hline 2 & PHT & Monthly & Stop ASM & & PHT resumed & Increased & Increased & Increased \\
\hline 3 & CBZ & $\begin{array}{l}\text { More than } 1 \\
\text { year }\end{array}$ & & & & & & \\
\hline 4 & LEV & Monthly & Stop ASM & LEV resumed & & Increased & Increased & \\
\hline 5 & & $\begin{array}{l}\text { More than } 1 \\
\text { year }\end{array}$ & & & & & & \\
\hline 6 & OXC, LEV & Monthly & & & & Decreased & Decreased & \\
\hline 7 & & $\begin{array}{l}\text { More than } 1 \\
\text { year }\end{array}$ & & & & & & \\
\hline 8 & & $\begin{array}{l}\text { More than } 1 \\
\text { year }\end{array}$ & & & & & & \\
\hline 9 & LEV & Monthly & Stop ASM & & & & & Decreased \\
\hline 10 & TPM & $\begin{array}{l}\text { More than } 1 \\
\text { year }\end{array}$ & & & $\begin{array}{l}\text { TPM dose } \\
\text { decrease }\end{array}$ & & & \\
\hline 11 & CBZ, LEV & Daily & & & & & Increased & Decreased \\
\hline 12 & CBZ, LEV & Daily & & & & & Increased & Decreased \\
\hline 13 & & $\begin{array}{l}\text { More than } 1 \\
\text { year }\end{array}$ & & & & & & Increased \\
\hline 14 & LTG, LEV & Monthly & $\begin{array}{l}\text { LTG dose } \\
\text { increase }\end{array}$ & $\begin{array}{l}\text { LEV dose } \\
\text { increase }\end{array}$ & $\begin{array}{l}\text { LTG dose } \\
\text { increase }\end{array}$ & Increased & Increased & Increased \\
\hline 15 & TPM, PHT & Monthly & & $\mathrm{PHT} \rightarrow \mathrm{LTG}$ & $\mathrm{TPM} \rightarrow$ LEV & & & \\
\hline
\end{tabular}




\section{Obstetric complications during pregnancy}

Among the 15 patients, 3 had vaginal bleeding in the first trimester, and one had slight elevations of glucose, protein and acetone bodies in the urine but these returned to normal on a re-check 2 weeks later.

Two patients had hypothyroidism at the mid-trimester and were on thyroxine supplement thereafter. One had anemia and was on regular treatment with re-check as well. Six patients had abnormal fetus ultrasound during the mid-trimester, four were found to have circular of the umbilical cord, and two showed slightly abnormal fetal growth compared to the reference.

There were also complications at the last trimester. Two patients had pre-eclampsia together with other accompanying conditions: gestational diabetes, and intrahepatic cholestasis, respectively. The patient with preeclampsia and intrahepatic cholestasis was found with fetal distress in the uterus, and had a premature delivery with third-degree amniotic fluid pollution. Other complications included intrahepatic cholestasis in one patient, and premature delivery with precipitate labor after a tonic-clonic seizure in one patient as stated above.

The data of delivery details were available for $13 \mathrm{pa}$ tients, including 11 receving Caesarean section, and 2 of vaginal delivery. The Caesarean section was conducted due to the complications at the trimesters or during delivery (e.g., protracted active phase) in 7 patients, following obstetrician's advice in 2 patients, and as to the demand of patients and their families in 2 patients. The average birth weight was $3,142.50 \pm 670.45 \mathrm{~g}$; the APGAR (Activity, Pulse, Grimace, Appearance, Respiration) grade ranged 7-10 points for all the patients. Two babies born at low birth weight were documented as 2,170 $\mathrm{g}$ and 2,000 $\mathrm{g}$, both being premature deliveries.

\section{Discussion}

In this preliminary study, the $15 \mathrm{WWE}$ of advanced maternal age had similar seizure frequency changes as reported data on the general WWE [2, 3], but more complications during pregnancy and delivery compared to the general WWE [4].

All patients in this study were above 35 years at pregnancy, with an average age of 36.32 years. A majority (73.33\%) of them were primiparas and the experience of abortion reflected their concerns about the disease, its potential influence on their offspring, and the adverse effects of ASM. Half of them had a college level or above and a stable job and income, indicating that this particular group of pregnant WWE had a specific lifestyle and role.

Previous studies have shown that, although the seizure frequency changes during pregnancy, the pattern of change is unclear and there is no decisive conclusion on whether the seizure burden is increased or decreased [2, $3]$. Here, we found that the increase of seizure frequency in the mid-trimester seemed more obvious than in other periods and was related to the increase in tonic-clonic seizures. Most of our patients had tonic-clonic seizures at a yearly level before pregnancy, and the frequency dramatically increased to a quarterly level in mid-trimester and continued till the last trimester. Mawer G et al. found that there are fewer women having convulsive seizures during the second half of pregnancy ( 21 weeks to term) than in the first 20 weeks. However, this rule does not apply to those on Lamotrigine or polytherapy [5]. Differently, in this study we compared the seizure frequency changes by trimesters, and did not find a trend of decrease in later pregnancy, neither was there any relationship with the influence of Lamotrigine and polytherapy. This may be due to the hormonal changes or drug concentration changes induced by them. Therefore, studies employing larger numbers of patients are needed to validate the phenomenon and clarify the underlying mechanisms of seizure frequency change during pregnancy.

Better control of seizures in patients with active epilepsy has always been the focus of our work. Consistent with previous studies, the majority of WWE were under monotherapy during pregnancy [2, 3]. Four patients stopped their medication when found pregnant. These patients need to be educated to stay on their drugs and never withdraw ASM by themselves. Educational programs should emphasize the benefits of continuing medication while notifying them the side effects as well. Meanwhile, for patients on stable epilepsy or already off their ASM, they also need to understand the risk of relapse and be notified to avoid certain factors that could induce seizure onset. In our study, one patient without ASM had a seizure reoccurrence, which caused premature delivery with precipitate labor.

Although there was no controlled group in our study, the obstetric complications during all the trimesters were common in this small sample, including vaginal bleeding, hypothyroidism, anemia, and pre-eclampsia. These complications have been reported previously in other studies, with a higher risk occurring in WWE especially those on medications during pregnancy $[4,5]$. In particular, patients in current study showed pre-eclampsia complicated with other conditions like gestational diabetes and intrahepatic cholestasis. The caesarean section rate was also high in our patients, mainly due to the complications occurring at trimesters or during delivery.

\section{Conclusions}

In conclusion, in this preliminary study of advanced maternal age and WWE, although the sample size was small and no control group was included, the results demonstrated common obstetric complications in WWE of advanced maternal age. Future studies with controls 
and large sample sizes are needed to further illustrate the phenomenon we observed from the 15 patients.

\section{Abbreviations}

ASM: Anti-seizure medications; APGAR: Activity, Pulse, Grimace, Appearance, Respiration; CBZ: Carbamazepine; LEV: Levetiracetam; LTG: Lamotrigine; OXC: Oxcarbazepine; PHT: Phenytoin; TPM: Topiramate; VPA: Valproate; WWE: Women with epilepsy

\section{Acknowledgements}

We thank all the colleagues previously worked or currently working on the epilepsy pregnancy registry of West China Hospital.

\section{Authors' contributions}

Hui Gao is the first author of this manuscript, participated in the data collection of the all the included individuals, analyzed the data, and drafted the manuscript. Nanya Hao participated the data collection of all the included individuals, made suggestions on the data analysis, and modified the manuscript. Mr. Shanrui Liu participated in the data collection and modified the manuscript. Prof. Dong Zhou is the corresponding author of this manuscript, designed the study and revised the manuscript. All authors have read and approved the final manuscript.

\section{Funding}

This work was supported by Key Research project of Sichuan Department of Science and Technology (No.2019YFS0211); National Natural Science Foundation of China (No.81901327); China Postdoctoral Science Foundation (No.208973); 1.3.5 project for disciplines and excellence of West China Hospital, Sichuan University (No.2017305).

\section{Availability of data and materials}

The datasets of this study are available from the corresponding author on reasonable request.

\section{Declarations}

\section{Ethics approval and consent to participate}

This study was approved by the Ethics Committee of West China Hospital, Sichuan University. Written informed consent was obtained from all the individuals enrolled in this study.

\section{Consent for publication}

The informed consent about publication was obtained from the patients.

\section{Competing interests}

Author Dong Zhou is a member of the Editorial Board for Acta Epileptologica. Author Dong Zhou was not involved in the journal's review of, or decisions related to this manuscript.

\section{Author details}

'Department of Neurology, West China Hospital, Sichuan University, Chengdu 610041, China. ${ }^{2}$ Clinical Medicine, West China School of Medicine Sichuan University, Chengdu 610041, China.

Received: 23 November 2020 Accepted: 8 July 2021

Published online: 31 July 2021

\section{References}

1. Zahn CA, Morrell MJ, Collins SD, Labiner DM, Yerby MS. Management issues for women with epilepsy: a review of the literature. Neurology. 1998;51(4): 949-56. https://doi.org/10.1212/WNL.51.4.949.

2. EURAP Study Group. Seizure control and treatment in pregnancy: observations from the EURAP epilepsy pregnancy registry. Neurology. 2006; 66(3):354-60. https://doi.org/10.1212/01.wnl.0000195888.51845.80.

3. Battino D, Tomson T, Bonizzoni E, Craig J, Lindhout D, Sabers A, et al. Seizure control and treatment changes in pregnancy: observations from the EURAP epilepsy pregnancy registry. Epilepsia. 2013;54(9):1621-7. https://doi. org/10.1111/epi.12302.

4. Borthen I, Eide MG, Daltveit AK, Gilhus NE. Obstetric outcome in women with epilepsy: a hospital-based, retrospective study. BJOG. 2011;118(8):95665. https://doi.org/10.1111/j.1471-0528.2011.03004.x.
5. Mawer G, Briggs M, Baker GA, Bromley R, Coyle H, Eatock J, et al. Pregnancy with epilepsy: obstetric and neonatal outcome of a controlled study. Seizure. 2010;19(2):112-9. https://doi.org/10.1016/j.seizure.2009.11.008.

6. Olafsson E, Hallgrimsson JT, Hauser WA, Ludvigsson P, Gudmundsson G. Pregnancies of women with epilepsy: a population-based study in Iceland. Epilepsia. 1998;39(8):887-92. https://doi.org/10.1111/j.1528-1157.1998.tb011 86.x.

7. Richmond JR, Krishnamoorthy P, Andermann E, Benjamin A. Epilepsy and pregnancy: an obstetric perspective. Am J Obstet Gynecol. 2004;190(2):3719. https://doi.org/10.1016/j.ajog.2003.09.020.

8. Endo S, Hagimoto H, Yamazawa H, Kajihara S, Kubota S, Kamijo A, et al. Statistics on deliveries of mothers with epilepsy at Yokohama City University Hospital. Epilepsia. 2004;45(Suppl 8):42-7. https://doi.org/10.1111/j.00139580.2004.458009.x.

9. Al Bunyan M, Abo-Talib Z. Outcome of pregnancies in epileptic women: a study in Saudi Arabia. Seizure. 1999;8(1):26-9. https://doi.org/10.1053/seiz.1 998.0239.

10. Fairgrieve $S D$, Jackson $M$, Jonas $P$, Walshaw $D$, White $K$, Montgomery $T L$, et al. Population based, prospective study of the care of women with epilepsy in pregnancy. BMJ. 2000;321(7262):674-5. https://doi.org/10.1136/ bmj.321.7262.674.

11. Canger R, Battino D, Canevini MP, Fumarola C, Guidolin L, Vignoli A, et al. Malformations in offspring of women with epilepsy: a prospective study. Epilepsia. 1999:40(9):1231-6. https://doi.org/10.1111/j.1528-1157.1999. tb00851.x.

12. Vajda FJ, O'brien TJ, Hitchcock A, Graham J, Cook M, Lander C, et al. Critical relationship between sodium valproate dose and human teratogenicity: results of the Australian register of anti-epileptic drugs in pregnancy. J Clin Neurosci. 2004;11(8):854-8. https://doi.org/10.1016/j.jocn.2004.05.003.

13. Vajda FJ, O'Brien TJ, Hitchcock A, Graham J, Lander C. The Australian registry of anti-epileptic drugs in pregnancy: experience after 30 months. J Clin Neurosci. 2003;10(5):543-9. https://doi.org/10.1016/50967-5868(03)00158-9.

14. Morrow J, Russell A, Guthrie E, Parsons L, Robertson I, Waddell R, et al. Malformation risks of antiepileptic drugs in pregnancy: a prospective study from the UK epilepsy and pregnancy register. J Neurol Neurosurg Psychiatry. 2006;77(2):193-8. https://doi.org/10.1136/jnnp.2005.074203.

15. Wyszynski DF, Nambisan M, Surve T, Alsdorf RM, Smith CR, Holmes LB, et al. Increased rate of major malformations in offspring exposed to valproate during pregnancy. Neurology. 2005;64(6):961-5. https://doi.org/10.1212/01. WNL.0000154516.43630.C5.

16. Guedes M, Canavarro MC. Characteristics of primiparous women of advanced age and their partners: a homogenous or heterogenous group? Birth. 2014;41(1):46-55. https://doi.org/10.1111/birt.12089.

17. Sauer MV. Reproduction at an advanced maternal age and maternal health. Fertil Steril. 2015;103(5):1136-43. https://doi.org/10.1016/j.fertnstert.2015.03. 004.

18. Allotey J, Aroyo-Manzano D, Lopez P, Viale L, Zamora J, Thangaratinam S. Global variation in pregnancy complications in women with epilepsy: a meta-analysis. Eur J Obstet Gynecol Reprod Biol. 2017;215:12-9. https:/doi. org/10.1016/j.jogrb.2017.05.016.

19. Nanya $\mathrm{H}$, Wei X, Yingying T, Wu M, Han J, Xu L, et al. Periconceptional folic acid supplementation among pregnant women with epilepsy in a developing country: A retro-prospective survey in China. Epilepsy Behav. 2015;44:27-34.

Ready to submit your research? Choose BMC and benefit from:

- fast, convenient online submission

- thorough peer review by experienced researchers in your field

- rapid publication on acceptance

- support for research data, including large and complex data types

- gold Open Access which fosters wider collaboration and increased citations

- maximum visibility for your research: over $100 \mathrm{M}$ website views per year

At BMC, research is always in progress.

Learn more biomedcentral.com/submission 